\title{
The Reliability of Bucket Wheel Excavator - Review of Random Mechanical Failures
}

\author{
Željko LAZAREVIĆ, Ivan ARANĐELOVIĆ, Snežana KIRIN
}

\begin{abstract}
Statistical regularity of random mechanical failures of the bucket wheel excavator will be considered based on dispatcher's reports about excavator-conveyorsspreader (ECS-III) on the Tamnava - West Field Open Cast Mine in Lazarevac (Serbia) system failures in the period from 2003 to 2011. This kind of failures happens suddenly due to undetectable defects, unexplainable causes, and unavoidable failures. Reliability functions $R(t)$, failure rate $\lambda(t)$ and failure density $f(t)$ of the bucket wheel excavator will be empirically determined. It was concluded that the random failures could be well approximated by the Exponential distribution. Below, serial reliability configuration of the BWE subsystem was analysed and the failure frequency as well as the values of the failure rate by subsystems were determined. Finally, proactive maintenance approach, which represents the latest innovation in the field of maintenance, will be presented. This approach to maintenance utilizes various technologies in order to achieve extension of operational life and elimination of reactive maintenance.
\end{abstract}

Keywords: bucket wheel excavator; mechanical failures; reliability

\section{INTRODUCTION}

In this article random failures of the bucket wheel excavator (BWE), which is in continuous excavatorconveyors-spreader (ECS-III) system on the Tamnava West Field Open Cast Mine, will be considered in the period 2003-2011. The system consists of:

- Excavator SchRs 900.25/6

- $\quad$ Belt wagon ARs/BRS $1600 /(28+50) \times 15$

- $\quad$ Spreader ARs $1400(22+60) \times 21$

- Belt conveyors width B-1500 mm.

The bucket wheel excavator is one of the most complex technical systems in the industry in general. It is characterized by a complex hierarchy of construction structure, high investment value, as well as productivity.

Serial connection of this system requires high reliability of components. In order to achieve this, maintenance of each component important for operation must be intensive, to assure the required level of system's reliability [6]. Operational conditions for systems at open cast mines are difficult and investment value of the system is high. This is why it is necessary to aim at the highest time and capacity utilization possible $[7,9,12,15,16]$.

Random mechanical failures of mining equipment may represent an important factor in coal production because this kind of failures occur unpredictably. Some of the reasons for the occurrence of such failures are undetectable defects, unexplainable causes and unavoidable failures.

According to a survey in the United States, approximately $46 \%$ of the major equipment repairs are due to an unscheduled failure. In addition to the impact on the project, other problems arise from these unexpected failures, including high costs for emergency repairs on a remote jobsite. However, there is a slight improvement in their prediction, which represents a significant saving in time and cost.

Mine equipment lifetime can be defined as working duration of equipment that is the period in which the equipment is in functional state.

Reliability is the probability that a component or system will perform a required function for a given period of time when used under stated operating condition. Although it is difficult to predict the time at which a piece of equipment fails due to the unscheduled critical failure, the time-dependent failure events demonstrate some statistical rules and the patterns of trend. Duane proposed the power law model on the failures of a complex repairable system [5]. Barabady and Kumar [3] used various statistical distributions to analyse the reliability of a crushing plant. The paper [2] identifies the rubber belt conveyer's reliability function, operating on mining machines removing overburden on the Tamnava - East Field Open Cast Mine, depending on the belt length and operating time.

Other examples of determination reliability function and distribution of lifetime are shown by Lazarević [14], Al-Hemyari [1], and Jiang [11], respectively. Liu [13] used the Weibull probability density functions to simulate reliability, optimize the design and reduce maintenance costs of the chain conveyor. Further, general principles and reliability tasks are given by $[17,18]$.

\section{TYPES OF MINING MAINTENANCE PROGRAMS}

Maintenance are the actions associated with equipment repair after it is broken. As we know, there are several types of mining maintenance programs:

- Preventive maintenance, that makes schedule of planned maintenance actions aimed at the prevention of breakdowns and failures,

- Reliability cantered maintenance, it represents process used to determine the maintenance requirements of any physical asset in its operating context. Also, it recognizes that all equipment in a facility is not of equal importance to either the process or facility safety [19],

- Predictive maintenance can be defined as "techniques that help determine the condition of in-service equipment in order to predict when maintenance should be performed" and it is used to define needed maintenance task based on quantified material/ equipment condition,

- Proactive maintenance is a more advanced approach in comparison to predictive maintenance that is based on machine condition determination in operation i.e. on the fact that most components have some kind of warning manifestation of immanent failure. 
Large lignite open cast mines in Germany, Poland, Hungary and Bulgaria are implementing so-called planned-preventive maintenance to a large extent, seeking to introduce proactive maintenance. Each open cast mine in these countries, introduces a method of machine condition determination in operation, utilizing various technologies in order to extend operational working life through monitoring data. These methods enable better insight into the state of individual devices, and their better utilization $[4,8,20]$.

\section{RELIABILITY IN GENERAL}

The reliability of a technical system is generally described by the reliability function $R(t)$ given by the Eq. (1):

$$
R(t)=\frac{f(t)}{\lambda(t)}
$$

Where: $f(t)$ - failure density function, $\lambda(t)$ - failure rate function.

Therefore, the reliability of a technical system is determined if two functions are known: reliability function $R(t)$ and failure rate function $\lambda(t)$. Most generally, the reliability function $R(t)$ can be mathematically described by Eq. (2) and can be applied to any failure density function $f(t)$.

$$
R(t)=\mathrm{e}^{-\int_{0}^{t} \lambda(t) \mathrm{d} t}
$$

Failure probability $P(T \leq t)$ in the function of the time is given by Eq. (3):

$$
P(T \leq t)=F(t)=1-R(t)
$$

Where: $F(t)$ - system failure function.

Then it is valid that the failure density function $f(t)$ equals the first derivative of the failure function $F(t)$, as described by Eq. (4):

$$
f(t)=\frac{\mathrm{d} F(t)}{\mathrm{d} t}
$$

In the reliability theory, failure density functions are applied for continuous processes as illustrated in Tab. 1 .

The best and "most suitable" failure density function $f(t)$, and thus the failure rate function $\lambda(t)$, as well as the reliability function $R(t)$ are determined based on experimentally obtained data. In that context, it is defined by Eq. (5):

$$
f_{e}(t)=\lambda_{e}(t) \times R_{e}(t)
$$

Where: $\lambda_{e}(t)$ - empirical failure rate function, $R_{e}(t)$ empirical reliability function.

If a technical system (in this case BWE) is renewed by maintenance or repairs, i.e. in case of so-called repairable systems, the expected time of failure-free work $E(T)$, known as the Mean Time Between Failures $(M T B F)$ is calculated by Eq. (6):

$$
M T B F=E(T)=\int_{0}^{\infty} R(t) \mathrm{d} t
$$

Table 1 Most common failure density distribution functions

\begin{tabular}{|l|c|c|}
\hline $\begin{array}{c}\text { Type of failure } \\
\text { distribution }\end{array}$ & $f(t)$ & $E(T)$ \\
\hline Exponential & $\lambda \cdot \mathrm{e}^{-\lambda \cdot t}$ & $\frac{1}{\lambda}$ \\
\hline Normal & $\frac{1}{\sigma \sqrt{2 \pi}} \cdot \mathrm{e}^{-\frac{1}{2}\left(\frac{t-\mu}{\sigma}\right)^{2}}$ & $\mu$ \\
\hline Lognormal & $\frac{1}{\sigma \cdot t \sqrt{2 \pi}} \cdot \mathrm{e}^{-\frac{1}{2}\left(\frac{\ln t-\mu}{\sigma}\right)^{2}}$ & $\mathrm{e}^{\mu+\frac{1}{2} \sigma^{2}}$ \\
\hline Weibull & $\frac{\beta\left(\frac{t-\gamma}{\eta}\right)^{\beta-1} \cdot \mathrm{e}^{-\left(\frac{t-\gamma}{\eta}\right)^{\sigma}}}{\eta\left(\frac{1}{\eta}\left(\frac{t-\gamma}{\eta}\right)^{\beta-1} \cdot \mathrm{e}^{-\frac{t-\gamma}{\eta}}\right.}$ & $\gamma+\eta \Gamma\left(\frac{1}{\beta}+1\right)$ \\
\hline Gama & $\frac{1}{\eta \Gamma(\beta)}(\eta \beta$ \\
\hline
\end{tabular}

\section{DETERMINATION OF EMPIRICAL FAILURE DENSITY FUNCTIONS, FAILURE RATE AND RELIABILITY}

Observed period of BWE random mechanical failures is $518 \mathrm{~h}$, because over $90 \%$ of this kind of failures happens during this period.

The empirical failure density function $f_{e}(t)$ equals the relation between the number of failures in the time interval $\Delta t_{j}$ and the total number of systems $n$, previously multiplied by the length of the time interval $\Delta t_{j}$. Then:

$$
f_{e}(t)=\frac{n_{1}\left(t_{j}\right)-n_{1}\left(t_{j}+\Delta t_{j}\right)}{n \cdot \Delta t_{j}}, t_{j} \leq t \leq\left(t_{j}+\Delta t_{j}\right)
$$

The empirical failure rate function $\lambda_{e}(t)$ will equal the relation between the number of failures in the time interval $\Delta t_{j}$ and the number of systems which did not fail at the end of the time interval $n_{1}\left(t_{j}+\Delta t_{j}\right)$ previously multiplied by the length of the time interval $\Delta t_{j}$ as determined by Eq. (8):

$$
\lambda_{e}(t)=\frac{n_{1}\left(t_{j}\right)-n_{1}\left(t_{j}+\Delta t_{j}\right)}{n_{1}\left(t_{j}\right) \cdot \Delta t_{j}}, t_{j} \leq t \leq\left(t_{j}+\Delta t_{j}\right)
$$

The empirical reliability function $R(t)$ will equal the relation between the number of systems which did not fail at the end of the time interval $n_{1}\left(t_{j}+\Delta t_{j}\right)$ and the total number of systems $n$, i.e. Eq. (9) is valid:

$$
R_{e}(t)=\frac{n_{1}\left(t_{j}+\Delta t_{j}\right)}{n}, t_{j} \leq t \leq\left(t_{j}+\Delta t_{j}\right)
$$

When the time intervals $\Delta t_{j}$ are equal, their optimal number $k$ can be determined by Eq. (10):

$k=1+3,3 \times \log n_{2}$

where: $n_{2}$ - total number of failures. 
Based on the data from dispatcher's reports about BWE failures for the year 2011 and in accordance with equation $(7 \div 10)$ the following relations are obtained and presented in Tab. 2 .

Table 2 Calculated values of empirical functions based on empirical data for year $2011\left(k=1+3,3 \times \log n_{2}\right)$

\begin{tabular}{|c|c|c|c|c|}
\hline$\Delta t_{j}^{b d s}(\mathrm{~h})$ & $\begin{array}{c}\text { Relative frequency of } \\
\text { failures }\end{array}$ & $f_{e}(t)$ & $\lambda_{e}(t)$ & $R_{e}(t)$ \\
\hline $0 \div 74$ & 18 & 0,0072 & 0,015 & 0,47 \\
\hline $74 \div 148$ & 5 & 0,002 & 0,006 & 0,32 \\
\hline $148 \div 222$ & 5 & 0,002 & 0,011 & 0,18 \\
\hline $222 \div 296$ & 2 & 0,0008 & 0,007 & 0,12 \\
\hline $296 \div 370$ & 2 & 0,0008 & 0,014 & 0,06 \\
\hline $370 \div 444$ & 1 & 0,0004 & 0,014 & 0,03 \\
\hline $444 \div 518$ & 1 & 0,0004 & - & 0 \\
\hline
\end{tabular}

At the same time, in Tab. 3, we have determined values of failure density, rate and reliability function but with different calculated values of time intervals $\Delta t_{j}$ i.e. (11):

$k=5 \times \log n_{2}$

Table 3 Calculated values of empirical functions based on empirical data for year $2011\left(k=5 \times \log n_{2}\right)$

\begin{tabular}{|c|c|c|c|c|}
\hline$\Delta t_{j}^{b d s}(\mathrm{~h})$ & $\begin{array}{c}\text { Relative frequency of } \\
\text { failures }\end{array}$ & $f_{e}(t)$ & $\lambda_{e}(t)$ & $R_{e}(t)$ \\
\hline $0 \div 67$ & 16 & 0,007 & 0,013 & 0,53 \\
\hline $67 \div 134$ & 7 & 0,0031 & 0,009 & 0,32 \\
\hline $134 \div 201$ & 4 & 0,0018 & 0,009 & 0,21 \\
\hline $201 \div 268$ & 3 & 0,0013 & 0,011 & 0,12 \\
\hline $268 \div 335$ & 1 & 0,0008 & 0,005 & 0,09 \\
\hline $335 \div 402$ & 1 & 0,0008 & 0,007 & 0,06 \\
\hline $402 \div 469$ & 1 & 0,0008 & 0,015 & 0,03 \\
\hline $469 \div 536$ & 1 & 0,0008 & - & 0 \\
\hline
\end{tabular}

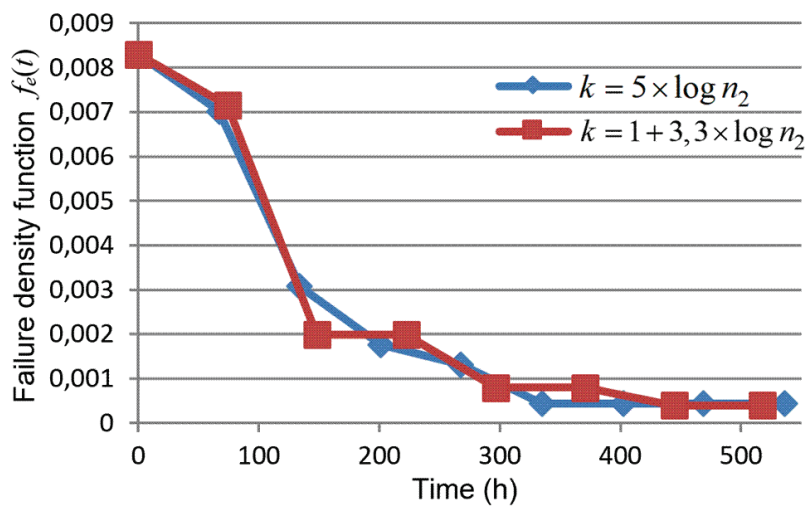

Figure 1 Failure density function $f_{e}(t)$ based on empirical data for year 2011

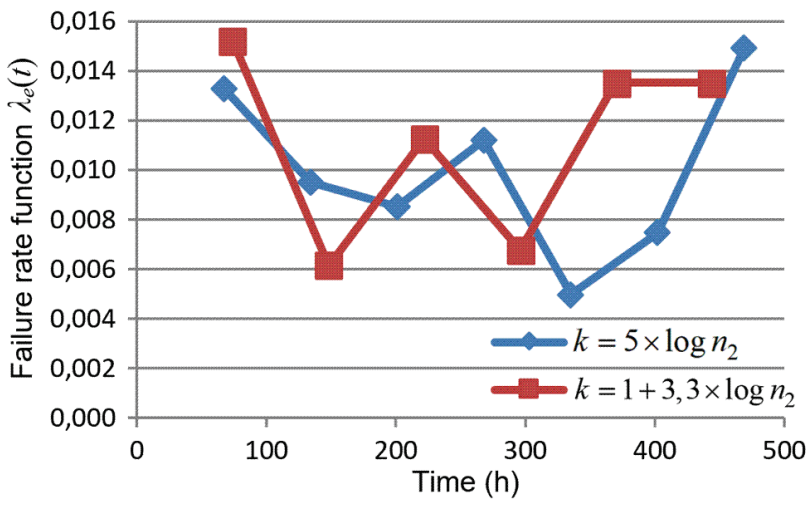

Figure 2 Failure rate function $\lambda_{e}(t)$ based on empirical data for year 2011
The graphs in Figs. 1, 2 and 3 show empirical functions of failure density, failure rate and failure reliability for different values of the time intervals $\Delta t_{j}$.

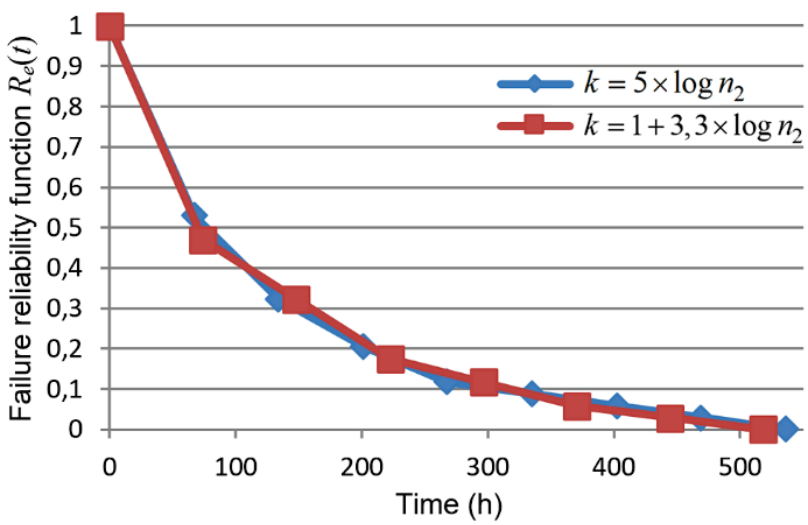

Figure 3 Failure reliability function $R_{e}(t)$ based on empirical data for year 2011

As seen in Fig. 3, the reliability can be well approximated by the Exponential distribution.

\section{EMPIRICAL FUNCTIONS APPROXIMATION BY THE EXPONENTIAL DISTRIBUTION}

Methods used to determine distribution, in order to approximate empirical data are: graphical and analytical.

In our case, we will use the analytical method by applying appropriate software "MathWave - EasyFit".

Figs. 4, 5 and 6 show the probability density, failure rate and reliability functions obtained from the empirical data and approximation based on the Exponential distribution.

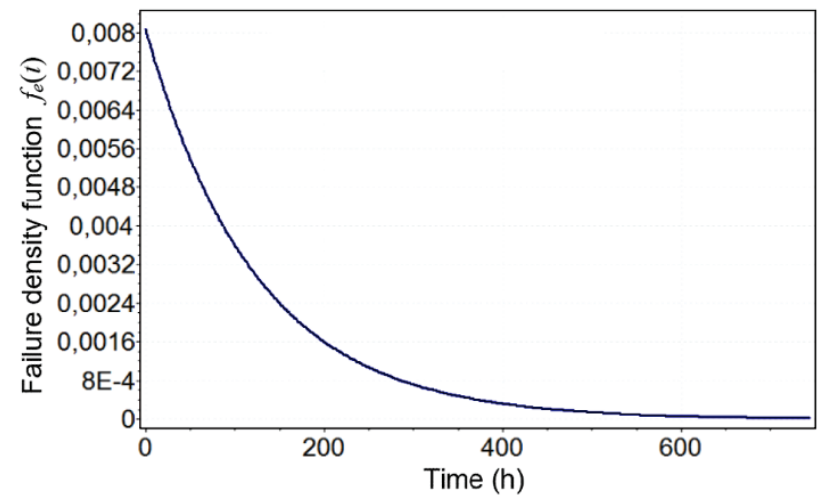

Figure 4 Probability density function, approximated for year 2011

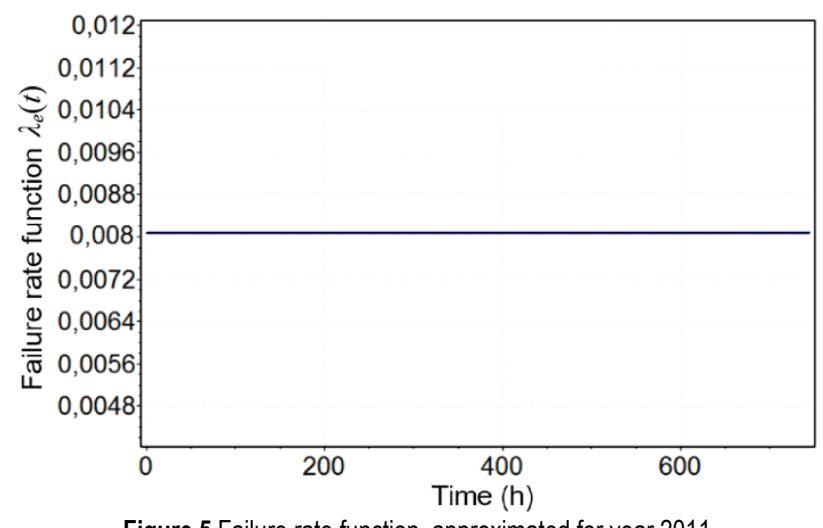

Figure 5 Failure rate function, approximated for year 2011 


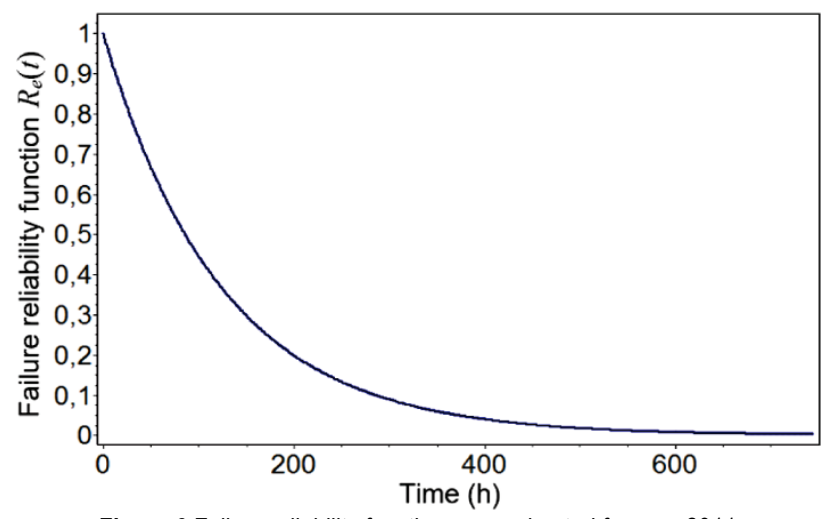

Figure 6 Failure reliability function, approximated for year 2011

In Fig. 7, Q-Q plot compares the observed data values on the vertical axis against the theoretical distribution quantiles on the horizontal axis.

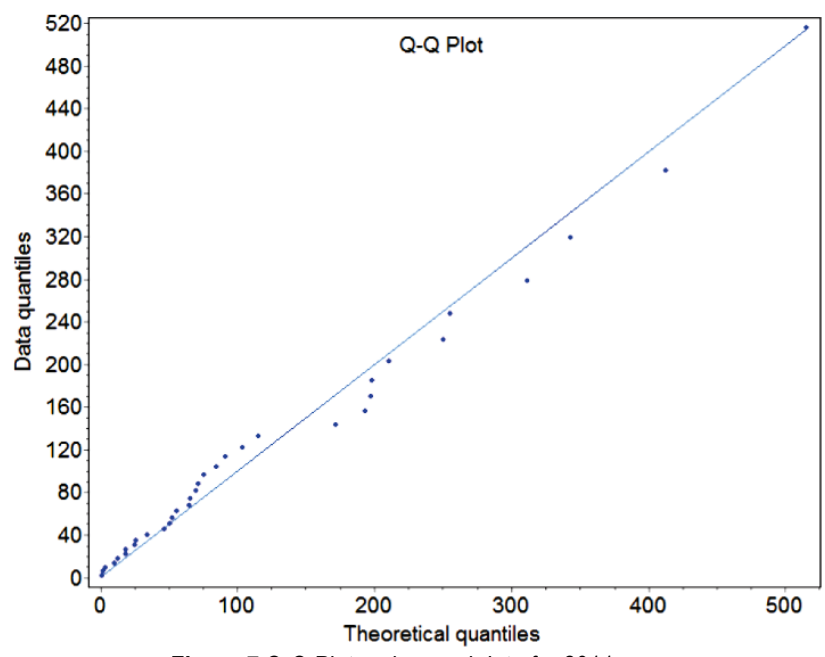

Figure 7 Q-Q Plot - observed data for 2011 year

Also, comparison of the observed distribution with theoretical one will be carried out in two tests: Kolmogorov-Smirnovtest and Anderson-Darling test.

The results show that exponential distribution with significance level $\alpha=0.05$ passes all tests. The results are presented in Fig. 8.

\begin{tabular}{|c|c|c|c|c|c|}
\hline \multicolumn{6}{|c|}{ Exponential [\#12] } \\
\hline \multicolumn{6}{|c|}{ Kolmogorov-Smirnov } \\
\hline $\begin{array}{l}\text { Sample Size } \\
\text { Statistic } \\
\text { P-Value } \\
\text { Rank }\end{array}$ & \multicolumn{5}{|l|}{$\begin{array}{l}7 \\
0,2008 \\
0,89184 \\
2\end{array}$} \\
\hline$\alpha$ & 0,2 & 0,1 & 0,05 & 0,02 & 0,01 \\
\hline Critical Value & 0,38148 & 0,43607 & 0,48342 & 0,53844 & 0,57581 \\
\hline Reject? & No & No & No & No & No \\
\hline \multicolumn{6}{|c|}{ Anderson-Darling } \\
\hline $\begin{array}{l}\text { Sample Size } \\
\text { Statistic } \\
\text { Rank }\end{array}$ & \multicolumn{5}{|l|}{$\begin{array}{l}7 \\
1,8741 \\
13\end{array}$} \\
\hline$\alpha$ & 0,2 & 0,1 & 0,05 & 0,02 & 0,01 \\
\hline Critical Value & 1,3749 & 1,9286 & 2,5018 & 3,2892 & 3,9074 \\
\hline Reject? & Yes & No & No & No & No \\
\hline
\end{tabular}

Figure 8 Test distribution results, based on data for year 2011

Equally, the derived exponential distributions for each year in the period from 2003 to 2011 pass all the test, too.
Reliability analysis of the bucket wheel excavator in the period from 2003 to 2011 shows constant failure rate function and the fact that the reliability of the above mentioned bucket wheel excavator can be well approximated by the Exponential distribution.

The reasons for the bucket wheel excavator random failure vary from undetectable defects, unexplainable causes to unavoidable failures. In the next chapter, the failure rates of the BWE subsystem parts and their contributions to the reliability and failure rate of the BWE will be determined, as follows.

\section{BUCKET WHEEL EXCAVATOR SUBSYSTEM FAILURE RATE}

Every technical system whose reliable operating depends on each of the subsystems within the system represents a model of serial reliability configuration.

Bucket wheel excavator is a very complex technical system, which consists of several subsystems and parts. Each subsystem represents the potential source of failures, random by the moment of occurrence and duration.

BWE subsystems ranked according to priority in terms of reliability are:

A - Material digging subsystem

B - Material transporting subsystem

$\mathrm{C}$ - Driving subsystem

D - Rotating slewing platform subsystem

E - Hoisting winch subsystem

F - Steel structure subsystem.

Fig. 9 shows a block diagram of a bucket wheel excavator defined with subsystems.

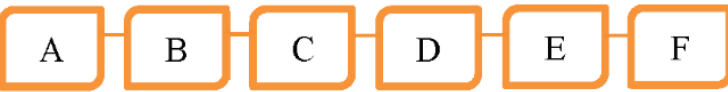

Figure 9 Block diagram of the BWE of serial reliability configuration

As an example, in Tab. 4 failures per particular subsystems for the year 2011 are shown.

It indicates that the BWE material transporting subsystem has most breakdowns.

Table 4 Failures per subsystems

\begin{tabular}{|c|c|c|c|c|c|c|}
\hline$t_{j}(\mathrm{~h})$ & $\mathrm{A}$ & $\mathrm{B}$ & $\mathrm{C}$ & $\mathrm{D}$ & $\mathrm{E}$ & $\mathrm{F}$ \\
\hline $0 \div 74$ & 7 & 10 & 1 & 0 & 0 & 0 \\
\hline $74 \div 148$ & 2 & 2 & 1 & 0 & 0 & 0 \\
\hline $148 \div 222$ & 0 & 3 & 2 & 0 & 0 & 0 \\
\hline $222 \div 296$ & 1 & 1 & 0 & 0 & 0 & 0 \\
\hline $296 \div 370$ & 1 & 1 & 0 & 0 & 0 & 0 \\
\hline $370 \div 444$ & 0 & 1 & 0 & 0 & 0 & 0 \\
\hline $444 \div 518$ & 0 & 0 & 1 & 0 & 0 & 0 \\
\hline$\sum$ & 11 & 18 & 5 & 0 & 0 & 0 \\
\hline
\end{tabular}

Fig. 10 shows the sequence of frequency of number of failures per subsystems.

If $T_{r i}$ is a randomly changeable variable representing the period of time by the moment of failure of $r^{\text {th }}$ subsystem, then the reliability of a technical system, composed of $m$ serially connected subsystems in one whole, on the basis of Eq. (3), is defined by:

$$
R(t)=P\left(T_{1}>t \cap T_{2}>t \cap \ldots \cap T_{r}>t \cap \ldots \cap T_{m}>t\right)
$$




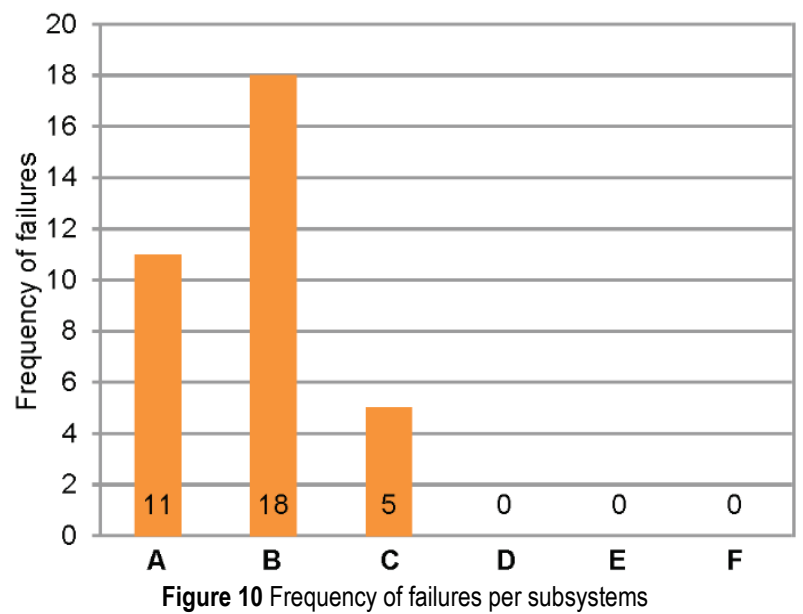

Assuming that subsystem failures are independent from one another, Eq. (12) will take the following form:

$$
R(t)=P\left(T_{1}>t\right) P\left(T_{2}>t\right) \ldots P\left(T_{r}>t\right) \ldots P\left(T_{m}>t\right)
$$

Thus it equals:

$$
R(t)=\prod R_{r}(t), \quad r=1,2,3, \ldots, m
$$

where: $R_{r}(t)$ - is the reliability of the $r^{\text {th }}$ subsystem.

On the basis Eqs. (2) it follows that:

$$
\begin{aligned}
& \lambda(t)=-\frac{\mathrm{d}[\ln R(t)]}{\mathrm{d} t}=-\frac{\mathrm{d}\left[\ln \prod R_{r}(t)\right]}{\mathrm{d} t}= \\
& =-\sum \frac{\mathrm{d}[\ln R(t)]}{\mathrm{d} t}=\sum_{r=1}^{m} \lambda_{r}(t), \quad r=1,2,3, \ldots, m
\end{aligned}
$$

Therefore, the failure rate function of the technical system $\lambda(t)$ equals the sum of the failure rate functions of individual subsystems $\lambda_{r}(t)$ which compose the system regardless of the density failure function of an individual subsystem $\lambda_{r}(t)$, on the assumption of independence of failures of subsystems. Failure rate values are shown in Tab. 5.

Table 5 Failure rate values per subsystems for year 2011

\begin{tabular}{|c|c|c|c|c|c|c|}
\hline$t_{j}(\mathrm{~h})$ & $\lambda_{\mathrm{A}}$ & $\lambda_{\mathrm{B}}$ & $\lambda_{\mathrm{C}}$ & $\lambda_{\mathrm{D}}$ & $\lambda_{\mathrm{E}}$ & $\lambda_{\mathrm{F}}$ \\
\hline $0 \div 74$ & 0.0031 & 0.0045 & 0.0004 & 0 & 0 & 0 \\
\hline $74 \div 148$ & 0.0032 & 0.0032 & 0.0016 & 0 & 0 & 0 \\
\hline $148 \div 222$ & 0 & 0.0048 & 0.0032 & 0 & 0 & 0 \\
\hline $222 \div 296$ & 0.004 & 0.004 & 0 & 0 & 0 & 0 \\
\hline $296 \div 370$ & 0.004 & 0.004 & 0 & 0 & 0 & 0 \\
\hline $370 \div 444$ & 0 & 0.0081 & 0 & 0 & 0 & 0 \\
\hline
\end{tabular}

Remark: Value in interval $444 \div 518(\mathrm{~h})$ is not taken into consideration because $R(t)=0$

Fig. 11 shows failure rate functions per individual subsystems and total failure rate functions for the technical system.

The carried out analysis of the BWE subsystems and individual components of the subsystem that caused the random failure (in the 2011 year) shows that mechanical parts can fail by the law of Exponential distribution with a constant failure rate.

The same conclusion for the period from 2003 to 2011 has been made.

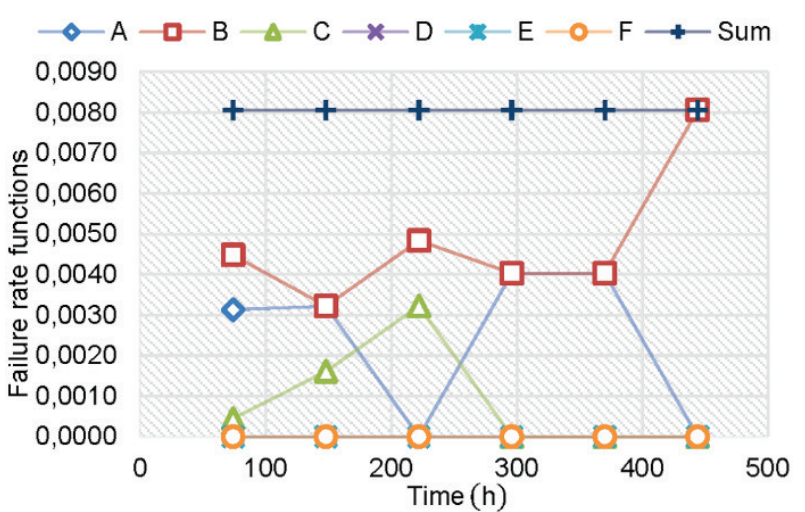

Figure 11 Rate functions per individual subsystem and total failure rate function for year 2011

\section{CONCLUSION}

The uptime of the system, whose failures are affected only by independent random factors, has exponential distribution. Thus, we conclude that factors affecting uptime of the bucket wheel excavator are mutually independent. In this case, when the failures are random, and when there is constant rate of failure, optimal procedure would be proper replacement of the parts in case of a failure i.e. reactive maintenance.

However, this approach has many disadvantages: increased cost due to unplanned downtime of equipment; increased labour cost, especially if overtime is needed; cost involved with repair or replacement of equipment; and possible secondary equipment or process damage because of equipment failure.

One of the latest innovations in the field of maintenance is proactive maintenance. The major part of a proactive programme is root cause failure analysis, which is the determination of the mechanisms and causes of machine or structure faults.

The successful proactive maintenance programme would, at first, find out irregularity on the structure (including all applicable methods for irregularity detection) then gradually eliminate problems in provided downtime for overhauling.

Introduction of proactive monitoring system on mining machines at open cast mines enables analysis of behaviour and the condition of units and components by review of acquired parameters, thus creating a situation for decision making related to the extension of operational life. Acquired parameters are a basis for decision making on revitalization, reconstruction or replacement of a unit or component, and also guidance for designing these machines [10].

One of the best properties of the proactive approach is a possibility of upgrading existing techniques implemented in predictive programmes. The developed procedures enable to predict behaviour of structure and potential failures, evaluating the reliability of structure under applied load.

Applying this approach to mining maintenance machines, we are much closer to the reliable operation of mining machines, particularly BWE. 


\section{REFERENCES}

[1] Al-Hemyari, Z. A. (2010). Some testimators for the scale parameter and reliability function of Weibull lifetime data. Proc ImechE Part O: Journal of Risk and Reliability, 224(3), 197-205. https://doi.org/10.1243/1748006XJRR299

[2] Bugarić, U., Tanasijević, M., Polovina, D., Ignjatović, D., \& Jovančić, P. (2014). Reliability of rubber conveyer belts as a part of the overburden removal system - case study: Tamnava-East field open cast mine. Technical Gazette, 21(5), 925-932.

[3] Barabady, J. \& Kumar, U. (2008). Reliability analysis of mining equipment: A case study of a crushing plant at Jajarm Bauxite Mine in Iran. Reliability Engineering and System Safety, 93, pp. 647-653. https://doi.org/10.1016/j.ress.2007.10.006

[4] Daničić, D., Lazarević, Ž., \& Mitrović, S. (2016). Proactive approach as contribution to system of preventing fatique failures. $13^{\text {th }}$ International Symposium Continuous Surface Mining, Belgrade, Serbia, 11-14 September, 45-59.

[5] Duane, J. T. (1964). Learning Curve Approach To Reliability Monitoring. IEEE Transactions on Aerospace, 2, 563-566. https://doi.org/10.1109/TA.1964.4319640

[6] Ignjatović, D. \& Jovančić, P. (2004). Extension of operational life of main mining equipment at EPS's open cast mines - Phase I Bucket wheel excavators. University of Belgrade, Faculty of Mining and Geology.

[7] Ignjatović, D. \& Jovančić, P. (2006). Case study Selection of optimal maintenance system at JPPK Kostolac. University of Belgrade, Faculty of Mining and Geology.

[8] Ignjatović, D. \& Jovančić, P. (2010). Proactive monitoring system for main mining mechanization at open cast mines. Structural Integrity and Life, 10(1), 11-19.

[9] Ivković, S., Ignjatović, D., Jovančić, P., \& Tanasijević, M. (2008). Monograph Equipment maintenance design at lignite open cast mines. University of Belgrade, Faculty of Mining and Geology.

[10] Ivković, S., Tanasijević, M., \& Ivković, D. (2005). Aktuelni problem rotornih bagera na kopovima uglja u Srbiji. Journal of applied engineering science, 3(7), 51-55.

[11] Jiang, H., Xie, M., \& Tang, L. C. (2008). On the odd Weibull distribution. Proc ImechE Part O: Journal of Risk and Reliability, 222(4), 583-594. https://doi.org/10.1243/1748006XJRR168

[12] Jovančić, P. (2007). Behaviour Diagnosis for Bucket Wheel Drive Assemblies at the Bucket Wheel Excavator with the Aim of Its Repair. PhD Thesis in Serbian, University of Belgrade, Faculty of Mining and Geology.

[13] Liu, D., Huang, L., Yue, W., \& Xu, X. (2009). Reliability simulation and design optimization for mechanical maintenance. Chinese Journal of Mechanical Engineering, 22(4), 594-601. https://doi.org/10.3901/CJME.2009.04.594

[14] Lazarević, Ž., Aranđelović, I., \& Kirin, S. (2015). An analysis of random mechanical failures of bucket wheel excavator. Structural Integrity and Life, 15(3), 143-146.

[15] Maneski, T. \& Ignjatović, D. (2004). Structural performance diagnostics. Structural Integrity and Life, 4(1), 3-7.

[16] Qin, L., Shen, X., Chen, X., \& Gao, P. (2017). Reliability Assessment of Bearings Based on Performance Degradation Values under Small Samples. Strojniški vestnik - Journal of Mechanical Engineering, 63(4), 248-254. http://dx.doi.org/10.5545/sv-jme.2016.3898

[17] Manfred, D. \& Wojbor, W. (1998). Introductory Statistics and Random Phenomena: Uncertainty, Complexity and Chaotic Behavior in Engineering and Science. Birkhauser.

[18] Tobias, P. A. \& Trindade, D. (2011). Applied Reliability. 3rd ed. Chapman and Hall/CRC.

[19] Todorović, J. (2003). Upravljanje održavanjem na bazi rizika. Journal of Applied Engineering Science, 1(1), 23-32.
[20] Zuber, N., Ličen, H., \& Klašnja-Milićević, A. (2009). Applied remote condition monitoring of BWE. Journal of Applied Engineering Science, 7(25), 31-40.

\section{Contact information:}

\section{Željko LAZAREVIĆ, PhD student}

University of Kragujevac,

Faculty of Engineering

Sestre Janjić 6, 34000 Kragujevac, Serbia

E-mail:zeljko_mas@yahoo.com

Ivan ARANĐELOVIĆ, PhD, full professor

University of Belgrade

Faculty of Mechanical Engineering

Kraljice Marije 16, 11000 Belgrade, Serbia

E-mail: iarandjelovic@mas.bg.ac.rs

\section{Snežana KIRIN, PhD}

Innovation center of the Faculty of Mechanical Engineering,

Kraljice Marije 16, 11000 Belgrade, Serbia

E-mail: snezanakirin@yahoo.com 